\title{
Nutritional status and related factors of patients with advanced lung cancer in northern China: a retrospective study
}

This article was published in the following Dove Medical Press journal: Cancer Management and Research

\author{
Ting $\mathrm{Ge}^{1, *}$ \\ Tie Lin ${ }^{2, *}$ \\ Jing Yang ${ }^{3}$ \\ Meng Wang' \\ 'Department of Respiratory Medicine, \\ Harbin Medical University Cancer \\ Hospital, Harbin, China; ${ }^{2}$ Department \\ of Surgery, The First Affiliated \\ Hospital of Harbin Medical University, \\ Harbin, China; ${ }^{3}$ Department of \\ Medicine, University of Alabama at \\ Birmingham, Birmingham, AL, USA \\ *These authors contributed equally to \\ this work
}

Correspondence: Meng Wang Department of Respiratory Medicine, Harbin Medical University Cancer Hospital, 150 HaPing Road, Nangang District, Harbin 150086, Heilongjiang Province, China

Email wangmeng@hrbmu.edu.cn
Background: Mortality of lung cancer in northern China has been increasing at an alarming speed. The consequences of malnutrition may include an increased risk of many complications. However, the nutritional status in advanced lung cancer patients is still unknown. So the aims of this research are to report on the prevalence of malnutrition in our population, the proportion of participants requiring nutrition interventions, and the relationship between nutritional status at diagnosis and overall survival (OS).

Patients and methods: We evaluated 495 patients with advanced lung cancer (stage IIIB and IV). Nutritional status was estimated by the Patient-Generated Subjective Global Assessment (PG-SGA). This study investigated the clinical significance of PG-SGA scores at admission by following OS. Kaplan-Meier survival analysis and the log-rank test were used to calculate OS. Univariate and multivariate analyses of the OS were performed using Cox analysis.

Results: Our results showed that $88.9 \%$ of the patients required nutrition intervention and $25.1 \%$ of the patients required improved nutrition-related symptom management and/or urgent nutritional support (PG-SGA score $\geq 9$ ). Factors related to malnutrition were age, sex, pathology, TNM stage, smoking condition, anemia, body mass index, pre-albumin, and albumin. The research outcomes indicated that PG-SGA score at admission was significantly associated with OS, which was still maintained when stratified by age and sex.

Conclusion: Malnutrition was prevalent in patients with advanced lung cancer. Poor nutritional status was associated with worse clinical outcomes.

Keywords: nutritional assessment, malnutrition, lung cancer, survival, PG-SGA

\section{Introduction}

The incidence and mortality of certain cancers in China have been increasing at an alarming speed. Lung cancer is still the most common incident cancer and the leading cause of cancer death. ${ }^{1}$ Numerous studies have demonstrated that the incidence of malnutrition among cancer patients is as high as $31 \%-97 \% .^{2-6}$ Studies on malnutrition in cancer patients are common in gastrointestinal tumors and relatively few in lung cancer patients. Xará et al found that the incidence of malnutrition among patients with non-small-cell lung cancer (NSCLC) was 35.7\%. ${ }^{7}$ The consequences of malnutrition may be reduced immune function, increased infection rates, decreased response and tolerance to treatment, higher health care costs, a lower quality of life, and reduced survival time. ${ }^{8-11}$ Furthermore, the relative risk of death from malnutrition has been found to be 1.8 times higher than for cancer patients without malnutrition. ${ }^{12}$ Hence, it is important to consider nutritional status in cancer management, since it decides the patient's tolerance for curative treatment. ${ }^{13}$ 
Traditional nutritional assessment is often difficult because non-nutritional factors can obscure the influences of actual nutrient deprivation. Therefore, the Subjective Global Assessment (SGA), an easy-to-use and a noninvasive clinical tool, has been developed. The SGA is a clinical technique that combines data from subjective and objective aspects of medical history (weight change, subcutaneous fat loss, muscle wasting, ankle or sacral edema, and ascites). ${ }^{14}$ The scored Patient-Generated Subjective Global Assessment (PG-SGA) is a modified version of the SGA, which is specifically designed for assessing the nutritional status in cancer patients. ${ }^{15-17}$ It contains additional problems regarding the existence of nutritional symptoms and short-term weight loss. The PG-SGA is a validated instrument to assess and monitor malnutrition, which is made up of both patient-reported and professional-reported items. The scored PG-SGA is formed from total PG-SGA score and global assessment. The total PG-SGA score is the sum of scores of the following seven items - weight loss, disease, food intake, nutrition impact symptoms, activities and function, metabolic demand, and physical examination. The scored PG-SGA has been accepted by the Oncology Nutrition Dietetic Practice Group of the American Dietetic Association as the standard for nutrition assessment for patients with cancer.

The sum of scores obtained in each domain of the PGSGA is used to determine the total PG-SGA score. After consultation, the dietitians rank the nutritional status of the patients as follows: 0-1, nutritional support not required and treatment in the future based on routine re-evaluation; 2-3, dietary guidance for patients and their families by a nutritionist, with assistance from nurses or other health care professionals based on symptom investigation and laboratory examination; 4-8, nutritional support provided by a dietitian with assistance from nurses or physicians according to the symptom questionnaire; $\geq 9$, urgent need for improved symptom management and/or nutritional support. ${ }^{18}$ Nutritional status is assessed by the PG-SGA category, which classifies patients into one of three categories: 0-1, well-nourished (PG-SGA A); 2-8, suspected malnutrition or moderate malnutrition (PG-SGA B); $\geq 9$, severely malnourished (PG-SGA C). ${ }^{19-21}$ The higher the PG-SGA score is, the greater is the risk for malnutrition. ${ }^{18}$

Malnutrition is a common phenomenon among patients with cancer, but it is often ignored in the treatment and follow-up care. ${ }^{22}$ The comprehensive approach to nutrition support may lead to improvements in nutritional status, quality of life, patient satisfaction, and treatment outcomes. The aims of the present study were to evaluate the nutritional status and possible relevant factors and provide the basic information for further studies regarding nutritional assessment of patients with lung cancer.

\section{Patients and methods}

This study was conducted in accordance with the Declaration of Helsinki and approved by the Ethics Committee at the Harbin Medical University. All patients gave written informed consent before their participation in the study.

\section{Patient and public involvement}

The participants of this study were lung cancer patients who were newly confirmed by pathological examination. Advanced lung cancer is defined as TNM stage IIIB and IV. We use the eighth edition lung cancer TNM staging system for staging. Patients who had only best supportive care, as well as those with cognitive impairment or other acute psychological problems, were excluded. Assessment of the nutritional status in patients was done within 24 hours after admission to the hospital. The subjects had records of weight history for the previous 6 months. Data on a wide range of variables including demographic factors, and nutritional status and nutrition-related symptoms were collected.

\section{Follow-up}

All patients were routinely followed every 3 months in the first 2 years. All patients were followed up using outpatient clinic check-ups. The latest follow-up was in June 2017, and the median follow-up duration was 12.6 months (range 1-60). Overall survival (OS) was calculated from the date of diagnosis until death or the last available follow-up. OS is considered to be the best efficacy endpoint in clinical trials for cancer, and it is the preferred endpoint when the patient's survival is adequately assessed. This study investigated the clinical significance of PG-SGA scores at admission by following OS.

\section{Statistical analysis}

We administered a PG-SGA standard questionnaire for patients with advanced lung cancer who were admitted to the Lung Medical Oncology Unit at Harbin Cancer Hospital. Statistical analysis was performed using SPSS version 17 (SPSS Institute, Inc.). The PG-SGA scores emerged as descriptive statistics (mean, SDs, and percentage). The degree of relationship among these factors and PG-SGA scores was statistically evaluated using the independent $t$-test (sex, TNM stage, smoking condition, albumin, and pre-albumin), Wilcoxon signed-rank test (age, pathology, and anemia), and Kruskal-Wallis test (body mass index [BMI]). Kaplan-Meier 
survival analysis and the log-rank test were used to calculate the OS. Univariate and multivariate analyses of the OS were performed using Cox analysis. Two-tailed $P<0.05$ was considered statistically significant.

\section{Results}

The study group consisted of 495 patients aged 28-79 years with advanced lung cancer. All patients with advanced lung cancer were confirmed by pathological diagnosis. Also, $70.7 \%$ (350) of the patients were male and 29.3\% (145) were female. Sixty-two percent (307) of the patients had a pathological diagnosis of NSCLC and 38.0\% (188) were pathologically diagnosed as small-cell lung cancer (SCLC). Patients with TNM stage IV constituted 66.7\% (330) and 33.3 (165) patients were stage IIIB. Also, 88.9\% (440) of the patients had a history of smoking and only $11.1 \%$ (55) had no history of smoking. There were 140 patients with BMI $<18.5 \mathrm{~kg} / \mathrm{m}^{2}$ and 115 with BMI $\geq 25.0 \mathrm{~kg} / \mathrm{m}^{2}$. There were 193 patients with anemia, 152 with pre-serum albumin $<20 \mathrm{mg} /$ $\mathrm{dL}$, and 132 with serum albumin $<35 \mathrm{~g} / \mathrm{L}$.

The PG-SGA score was calculated and the scores ranged between 0 and 35 . Based on the total scores, nutritional status of the patients was divided into four parts. In this study, only $11.1 \%$ of the patients did not need nutritional intervention (scores $0-1$ ), $10.5 \%$ of them needed health education (scores $2-3$ ), 53.3\% of them needed nutritional support (scores 4-8), and $25.1 \%$ needed nutrition-related symptom management and (or) nutritional support urgently (score $\geq 9$ ). Table 1 summarizes the nutritional status of the study group. Participants received corresponding nutrition intervention based on the PG-SGA score after completing the PG-SGA.

Weight loss was the most frequently used nutritional assessment method, which was measured solely or in combination with PG-SGA. ${ }^{23-25}$ In our study, severe weight loss was observed in $7 \%$ of the patients (weight loss of $>10 \%$ in 1 month or $>20 \%$ in 6 months), and weight loss continued to occur in $80.4 \%$ of the patients. Also, $58.8 \%$ of the patients had varying degrees of difficulty in eating food. Nearly

Table I Patient-Generated Subjective Global Assessment classification $(\mathrm{N}=495)$

\begin{tabular}{|l|l|l|}
\hline Classification (score) & Cases (n) & $\%$ \\
\hline Without intervention (0-1) & 55 & II.I \\
Need health education (2-3) & 52 & 10.5 \\
Need nutritional support (4-8) & 264 & 53.3 \\
Need symptom management and/or & 124 & 25.1 \\
nutritional support $(\geq 9)$ & & \\
\hline
\end{tabular}

half $(50.1 \%)$ of the patients had reduced food intake, $6.5 \%$ had pap food, and $2.2 \%$ had only liquid food. Only $17.2 \%$ of the patients had no nutrition impact symptoms. Among all patients, $57.2 \%$ had choking and $59 \%$ had appetite loss, vomiting, and diarrhea. Overall, $62.4 \%$ of the patients had impaired function and ability. Among them, 7.3\% could lie or sit for more than half a day. Of the subjects, $61.8 \%$ reported fat loss, with the condition being severe in $11.7 \%$. Additionally, $16.4 \%$ of the patients experienced severe stress and $28.3 \%$ of the patients had pleural effusion or ascites. The characteristics of the patient cohort are summarized in detail in Table 2.

Table 2 Patient-Generated Subjective Global Assessment content $(\mathrm{N}=495)$

\begin{tabular}{|c|c|c|}
\hline Characteristics of patient & Cases (n) & $\%$ \\
\hline \multicolumn{3}{|l|}{ Weight loss ratio $(\%)^{18}$} \\
\hline $0-1.9$ & 186 & 37.6 \\
\hline $2-2.9$ in I month or $2-5.9$ in 6 months & 45 & 9.1 \\
\hline $3-4.9$ in I month or 6-9.9 in 6 months & 136 & 27.5 \\
\hline $5-9.9$ in I month or 10-19.9 in 6 months & 93 & 18.8 \\
\hline$\geq 10$ in 1 month or $\geq 20$ in 6 months & 35 & 7.0 \\
\hline \multicolumn{3}{|l|}{ Body weight loss in the recent 2 weeks } \\
\hline Yes & 398 & 80.4 \\
\hline No & 97 & 19.6 \\
\hline \multicolumn{3}{|l|}{ Food intake } \\
\hline Normal & 204 & 41.2 \\
\hline Reduced food intake & 248 & 50.1 \\
\hline Pap & 32 & 6.5 \\
\hline Liquid food & 11 & 2.2 \\
\hline \multicolumn{3}{|l|}{ Nutrition impact symptoms } \\
\hline No & 85 & 17.2 \\
\hline Nausea and fullness & 45 & 9.1 \\
\hline Choking & 283 & 57.2 \\
\hline Appetite loss/vomiting/diarrhea & 292 & 59.0 \\
\hline \multicolumn{3}{|l|}{ Functional capacity } \\
\hline Normal & 186 & 37.6 \\
\hline Minor activities & 241 & 48.7 \\
\hline Lying or sitting for less than half a day & 32 & 6.4 \\
\hline Lying or sitting for more than half a day & 36 & 7.3 \\
\hline \multicolumn{3}{|l|}{ Loss of fat (tricipital skinfold thickness) ${ }^{18}$} \\
\hline No & 189 & 38.2 \\
\hline Mild & 142 & 28.7 \\
\hline Moderate & 106 & 21.4 \\
\hline Severe & 58 & 11.7 \\
\hline \multicolumn{3}{|l|}{ Stress } \\
\hline No & 256 & 51.7 \\
\hline Moderate & 158 & 31.9 \\
\hline Severe & 81 & 16.4 \\
\hline \multicolumn{3}{|c|}{ Body fluids (pleural effusion and ascites) ${ }^{18}$} \\
\hline No & 355 & 71.7 \\
\hline Mild & 82 & 16.6 \\
\hline Moderate & 42 & 8.5 \\
\hline Severe & 16 & 3.2 \\
\hline
\end{tabular}


Table 3 summarizes the relationship between PG-SGA scores and possible related factors. An elevated PG-SGA score was associated with age $\geq 60$ years $(P=0.026)$, female patients $(P<0.001)$, SCLC, smoking, presence of anemia $(P<0.001)$, higher TNM stage $(P<0.001)$, and lower BMI, pre-albumin, and albumin.

The treatment regimen for 495 patients with advanced lung cancer is shown in Table 4.

The median follow-up duration was 12.6 months (range 1-60). Of all participants, 413 patients had died. Patients with the PG-SGA scores of $0-1$ had significantly longer mean survival compared to patients with PG-SGA scores greater than $1(P<0.001$; Figure 1$)$. In age- and sex-matched analysis, the PG-SGA scores were still associated with OS $(P<0.001$, respectively; Figure 2$)$. An elevated PG-SGA score was associated with reduced survival of both young and old

Table 3 Analysis of PG-SGA score with factors affecting nutritional status

\begin{tabular}{|c|c|c|c|c|}
\hline \multirow{2}{*}{\multicolumn{2}{|c|}{ Cases (n) }} & \multirow{2}{*}{\begin{tabular}{|l}
$\begin{array}{l}\text { PG-SGA } \\
\text { score }\end{array}$ \\
$\begin{array}{l}\text { Median } \pm \\
\text { SD }\end{array}$ \\
\end{tabular}} & \multirow{2}{*}{$\begin{array}{l}\text { Statistical } \\
\text { value }\end{array}$} & \multirow[t]{2}{*}{$P$-value } \\
\hline & & & & \\
\hline Age (years) & & & & \\
\hline$\geq 60$ & 300 & $8 \pm 2.20$ & & \\
\hline$<60$ & 195 & $6 \pm 1.60$ & $u=-2.226$ & 0.026 \\
\hline Sex & & & & \\
\hline Male & 350 & $6 \pm 0.96$ & & \\
\hline Female & 145 & $7 \pm 1.12$ & $\mathrm{t}=-9.254$ & $<0.001$ \\
\hline Type of lung cancer & & & & \\
\hline NSCLC & 307 & $5 \pm 0.80$ & & \\
\hline SCLC & 188 & $7 \pm 0.64$ & $u=-9.605$ & $<0.001$ \\
\hline TNM stage & & & & \\
\hline III B & 165 & $5 \pm 1.09$ & & \\
\hline IV & 330 & $8 \pm 1.02$ & $\mathrm{t}=18.893$ & $<0.001$ \\
\hline Smoking condition & & & & \\
\hline Yes & 440 & $7 \pm 0.91$ & & \\
\hline No & 55 & $4 \pm 1.17$ & $\mathrm{t}=15.598$ & $<0.001$ \\
\hline Anemia & & & & \\
\hline Yes & 193 & $7 \pm 0.73$ & & \\
\hline No & 302 & $6 \pm 0.47$ & $u=-12.006$ & $<0.001$ \\
\hline BMI $\left(\mathrm{kg} / \mathrm{m}^{2}\right)$ & & & & \\
\hline$<18.5$ & 140 & $7 \pm 0.67$ & & \\
\hline$\geq 18.5$ and $<25.0$ & 240 & $6 \pm 0.42$ & & \\
\hline$\geq 25.0$ & 115 & $4 \pm 0.68$ & & $<0.001$ \\
\hline Pre-albumin $(\mathrm{mg} / \mathrm{dL})$ & & & & \\
\hline$<20 \mathrm{mg} / \mathrm{dL}$ & 152 & $8 \pm 0.49$ & & \\
\hline$\geq 20 \mathrm{mg} / \mathrm{dL}$ & 343 & $6 \pm 0.54$ & $t=55.708$ & $<0.001$ \\
\hline Albumin & & & & \\
\hline$<35 \mathrm{~g} / \mathrm{L}$ & 132 & $8 \pm 0.48$ & & \\
\hline$\geq 35 \mathrm{~g} / \mathrm{L}$ & 363 & $6 \pm 0.48$ & $t=40.808$ & $<0.001$ \\
\hline
\end{tabular}

Abbreviations: BMI, body mass index; NSCLC, non-small-cell lung cancer; PGSGA, Patient-Generated Subjective Global Assessment; SCLC, small-cell lung cancer. lung cancer patients. Univariate and multivariate analyses for OS outcomes are shown in Table 5.

\section{Discussion}

Malnutrition frequently coexists in cancer patients. The results of our study (Table 1) showed that $25.1 \%$ of the patients need nutrition-related symptom management and/ or nutritional support urgently. Moreover, only $11.1 \%$ of the patients with advanced lung cancer do not need nutritional intervention. Our findings indicate that malnutrition is prevalent in advanced lung cancer patients, and these patients require timely nutrition education and guidance,

Table 4 Treatment regimen for advanced lung cancer

\begin{tabular}{|l|l|}
\hline $\begin{array}{l}\text { Type of lung } \\
\text { cancer }\end{array}$ & Treatment regimen \\
\hline NSCLC & $\begin{array}{l}\text { Targeted therapy } \\
\text { Immunotherapy } \\
\text { Immunotherapy and chemotherapy } \\
\text { Chemotherapy (pemetrexed + cisplatin/gemcitabine } \\
+ \text { cisplatin } \\
\text { /Paclitaxel + cisplatin/vinorelbine + cisplatin/ } \\
\text { docetaxel + cisplatin/pemetrexed + carboplatin/ } \\
\text { gemcitabine + carboplatin/paclitaxel + carboplatin/ } \\
\text { gemcitabine/docetaxel) } \\
\text { Radiotherapy (three-dimensional conformal } \\
\text { radiation therapy) } \\
\text { Chemotherapy and radiotherapy } \\
\text { Chemotherapy (etoposide + cisplatin/etoposide } \\
+ \text { carboplatin/irinotecan + cisplatin/paclitaxel/ } \\
\text { docetaxel/gemcitabine) } \\
\text { Chemotherapy and radiotherapy (three- } \\
\text { dimensional conformal radiation therapy) }\end{array}$ \\
\hline
\end{tabular}

Abbreviations: NSCLC, non-small-cell lung cancer; SCLC, small-cell lung cancer.

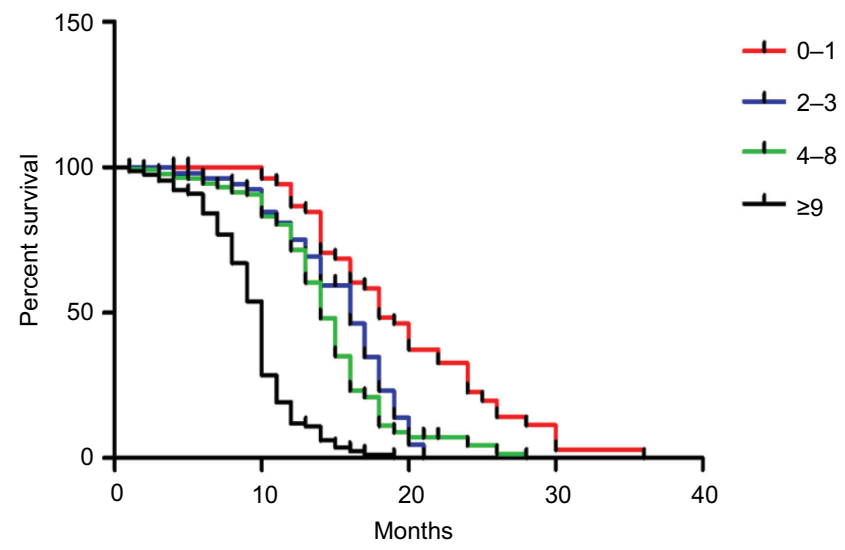

Figure I Kaplan-Meier survival curves by PG-SGA scores in patients with advanced lung cancer.

Notes: Log-rank between-group comparison $P<0.001$. Cox analysis showed that the Cox risk ratio was 2.128 (95\% Cl: $1.855-2.440)$.

Abbreviation: PG-SGA, Patient-Generated Subjective Global Assessment. 
A

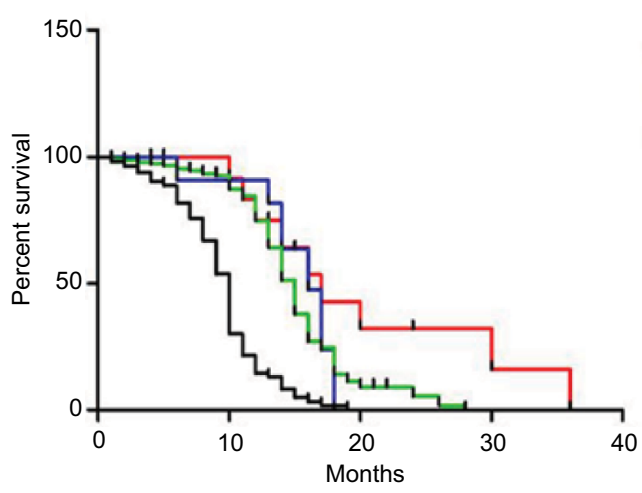

C

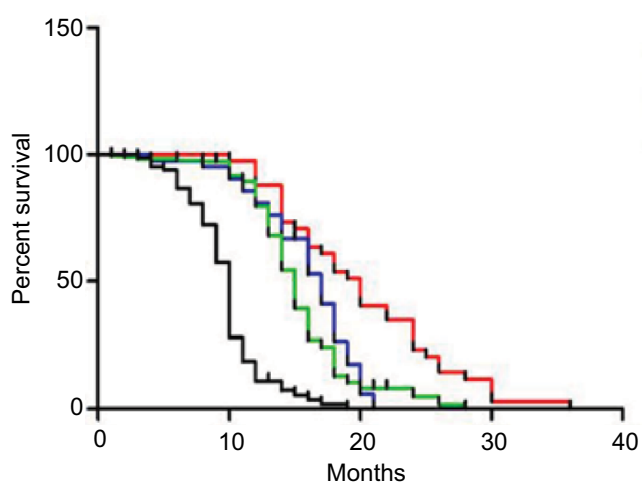

B
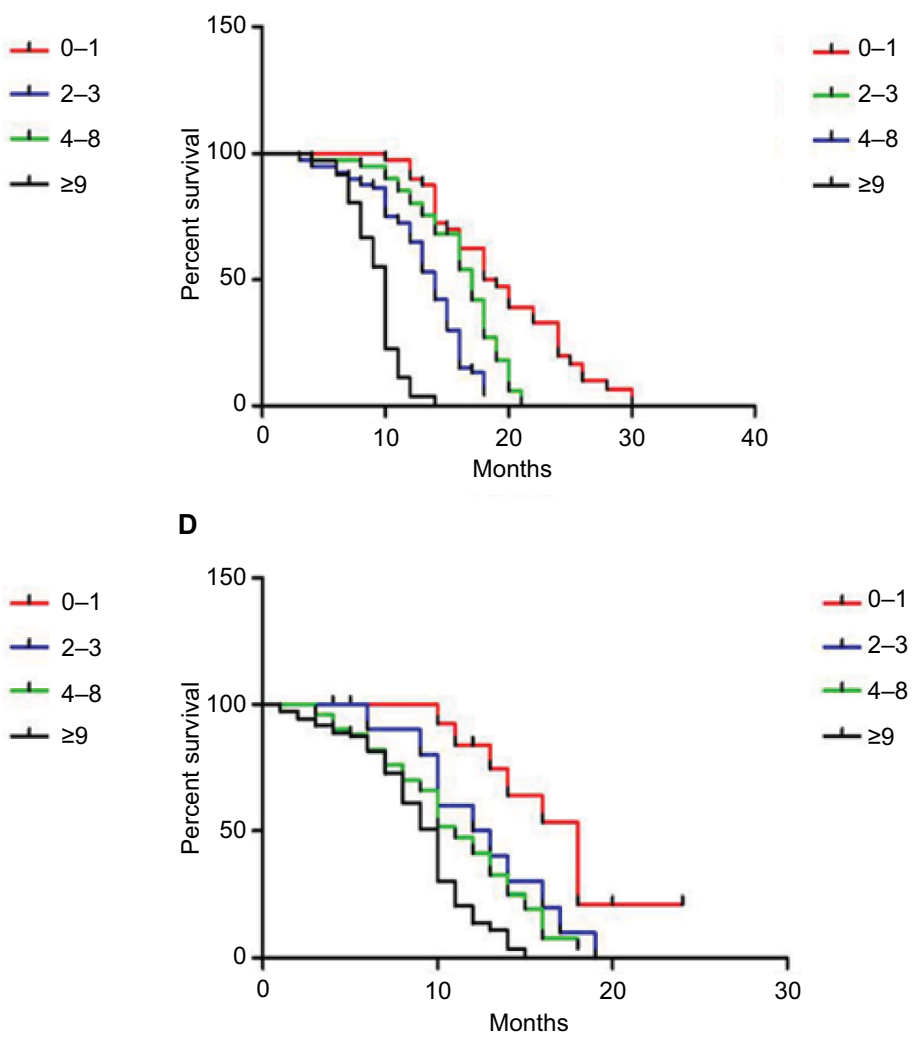

D

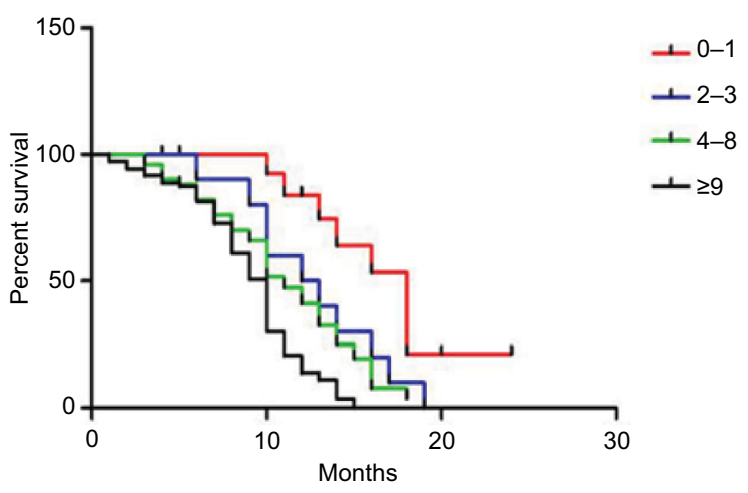

Figure 2 Overall survival based on PG-SGA scores in patients aged $\geq 60$ years (A), $<60$ years (B), male patients (C), and female patients (D), respectively. Abbreviation: PG-SGA, Patient-Generated Subjective Global Assessment.

treatment for symptoms, such as drug interventions, and proper nutritional support.

Data summarized in Table 2 reveal that advanced lung cancer patients experience various degrees of weight loss. Severe weight loss was found in $7 \%$ of the patients (weight loss of $>10 \%$ in 1 month or $>20 \%$ in 6 months), and weight loss continued to occur in nearly four-fifths $(80.4 \%)$ of the patients. Weight loss indicates poor treatment response and contributes to mortality in lung cancer. ${ }^{26-28}$ In this study, $58.8 \%$ of the patients had difficulty with eating food, including $6.5 \%$ who could consume pap food and $2.2 \%$ who could consume only liquid food. Many patients with advanced lung cancer were consuming diets that would likely be insufficient to maintain weight even in healthy individuals. The results showed that $61.8 \%$ of the patients had a reduction in fat, with the most severe case showing a reduction of $11.7 \%$. Patients with lung cancer have higher consumption of protein and fat, which could lead to weight loss. Significant weight loss may result in increased rate of complications, such as impaired wound healing, reduced immune function, and decreased tolerance to surgery, radiotherapy, and chemotherapy, as well as reduced quality of life. ${ }^{29-31}$ Our data show that $82.8 \%$ of the advanced lung cancer patients had nutrition impact symptoms, including nausea or fullness $(9.1 \%)$, choking (57.2\%), appetite loss, vomiting, and diarrhea (59.0\%). These symptoms might relate with metabolic problems that are induced by advanced lung cancer. Additionally, $16.4 \%$ of the patients experienced severe stress; these patients should be given appropriate psychological intervention treatment. Also, $28.3 \%$ of the patients had pleural effusion or ascites. The cause of pleural effusion or ascites might be the following: lung cancer metastasizes to the pleura, resulting in increased pleural secretion, which leads to effusion, and patients with advanced lung cancer may suffer from malnutrition and decrease in serum albumin, which may lead to effusion.

The present study demonstrates that elderly patients ( $\geq 60)$ and female patients would be more likely to have malnutrition. The research shows that patients who had a history of smoking showed higher malnutrition than the patients who had no history of smoking. Malnutrition may be associated with smoking as it is the inducing factor of many diseases. Therefore, more attention should be paid to 
Table 5 Univariate and multivariate analyses for OS outcomes

\begin{tabular}{|c|c|c|c|}
\hline \multirow{2}{*}{$\begin{array}{l}\text { Characteristics of } \\
\text { patient }\end{array}$} & \multicolumn{3}{|l|}{ OS } \\
\hline & HR & $95 \% \mathrm{Cl}$ & $P$-value \\
\hline \multicolumn{4}{|l|}{ Univariate analysis } \\
\hline \multicolumn{4}{|l|}{ Age (years) } \\
\hline$\geq 60$ vs $<60$ & 1.297 & $1.065-1.58 \mid$ & 0.010 \\
\hline \multicolumn{4}{|l|}{ Sex } \\
\hline Male vs female & 0.457 & $0.367-0.569$ & $<0.001$ \\
\hline \multicolumn{4}{|l|}{ PG-SGA } \\
\hline $0-1$ vs $2-3$ vs $4-8$ vs $\geq 9$ & 2.128 & $1.855-2.440$ & $<0.001$ \\
\hline \multicolumn{4}{|l|}{ Type of lung cancer } \\
\hline NSCLC vs SCLC & 3.501 & $2.824-4.339$ & $<0.001$ \\
\hline \multicolumn{4}{|l|}{ TNM stage } \\
\hline III B vs IV & I.I44 & $0.932-1.405$ & 0.197 \\
\hline \multicolumn{4}{|l|}{ Smoking condition } \\
\hline \multicolumn{4}{|l|}{ Anemia } \\
\hline Yes vs no & 1.125 & $0.922-1.373$ & 0.245 \\
\hline \multicolumn{4}{|l|}{ BMI $\left(\mathrm{kg} / \mathrm{m}^{2}\right)$} \\
\hline $\begin{array}{l}<18.5 \text { vs } \geq 18.5 \text { and }<25.0 \\
\text { vs } \geq 25.0\end{array}$ & 1.098 & $0.960-1.256$ & 0.173 \\
\hline \multicolumn{4}{|l|}{ Pre-albumin (mg/dL) } \\
\hline$<20$ vs $\geq 20$ & 1.038 & $0.843-1.277$ & 0.726 \\
\hline \multicolumn{4}{|l|}{ Albumin $(g / L)$} \\
\hline$<35$ vs $\geq 35$ & 0.562 & $0.45 I-0.700$ & $<0.001$ \\
\hline \multicolumn{4}{|l|}{ Multivariate analysis } \\
\hline \multicolumn{4}{|l|}{ Age (years) } \\
\hline$\geq 60$ vs $<60$ & 0.758 & $0.556-1.003$ & 0.079 \\
\hline \multicolumn{4}{|l|}{ Sex } \\
\hline Male vs female & 0.338 & $0.259-0.441$ & $<0.001$ \\
\hline PG-SGA & & & \\
\hline $0-I$ vs $2-3$ vs $4-8$ vs $\geq 9$ & 1.857 & $1.583-2.180$ & $<0.001$ \\
\hline Type of lung cancer & & & \\
\hline NSCLC vs SCLC & 2.805 & $2.24 I-3.510$ & $<0.001$ \\
\hline Albumin (g/L) & & & \\
\hline$<35$ vs $\geq 35$ & 0.687 & $0.548-0.861$ & 0.001 \\
\hline
\end{tabular}

Abbreviations: BMI, body mass index; NSCLC, non-small-cell lung cancer; OS, overall survival; PG-SGA, Patient-Generated Subjective Global Assessment; SCLC, small-cell lung cancer.

the patients who have a history of smoking, and smoking cessation support should be provided for these patients. Furthermore, we found that the PG-SGA score was associated with OS. Patients with PG-SGA scores of $0-1$ had significantly longer mean survival. These findings were supported by other studies, which also found an association between nutritional status and clinical outcome. Alifano et al reported that nutritional status and tumor immune microenvironment determine the outcome of resected NSCLC. ${ }^{32}$ Tan et al also found that nutritional status, which was assessed by PG-SGA, might be a determinant of prognosis in patients with advanced cancer. ${ }^{33}$ Given these results, we speculated that the PG-SGA score might exert more potent prognostic value.
A potential limitation of the current study is that it was a single-center analysis, and we lacked the data of progressionfree survival, though OS is considered the gold standard endpoint for cancer prognosis study. Therefore, our findings might need to be confirmed with additional outcome measures. Further prospective studies are warranted to assess whether the PG-SGA can predict the risk of poor clinical outcomes such as dose-intensity of chemotherapy, quality of life, and survival in lung cancer patients. Patients with a high risk of malnutrition should be given more attention, and improvement of the nutritional status of patients with advanced lung cancer has beneficial effects on their quality of life.

\section{Conclusion}

The present study aimed to assess the nutritional status of patients with advanced lung cancer, particularly those at a higher risk of malnutrition, such as elderly patients, female patients, SCLC patients, patients of TNM stage IV, and smokers, and poor nutritional status was associated with worse clinical outcomes.

Patients with a high risk of malnutrition should be given more attention; their nutritional status should be evaluated and they should be given nutrition education and necessary nutritional support in time. Improvement of the nutritional status of patients with advanced lung cancer may have beneficial effects on their quality of life.

The present study has several limitations. First, treatment of patients in this study is different, which may lead to differences in OS. Second, the heterogeneity of patients with NSCLC and SCLC has a certain impact on the OS of patients. These should be taken care of in the future.

\section{Author contributions}

All authors contributed to data analysis, drafting and revising the article, gave final approval of the version to be published, and agree to be accountable for all aspects of the work.

\section{Disclosure}

The authors report no conflicts of interest in this work.

\section{References}

1. Bode AM, Dong Z, Wang H. Cancer prevention and control: alarming challenges in China. Natl Sci Rev. 2016;3(1):117-127.

2. Huhmann MB, Cunningham RS. Importance of nutritional screening in treatment of cancer-related weight loss. Lancet Oncol. 2005;6(5):334-343.

3. Segura A, Pardo J, Jara C, et al. An epidemiological evaluation of the prevalence of malnutrition in Spanish patients with locally advanced or metastatic cancer. Clin Nutr. 2005;24(5):801-814. 
4. Abe Vicente M, Barão K, Silva TD, Forones NM. What are the most effective methods for assessment of nutritional status in outpatients with gastric and colorectal cancer? Nutr Hosp. 2013;28(3):585-591.

5. Malihi Z, Kandiah M, Chan YM, et al. Nutritional status and quality of life in patients with acute leukaemia prior to and after induction chemotherapy in three hospitals in Tehran, Iran: a prospective study. $J$ Hum Nutr Diet. 2013;26(Suppl):123-131.

6. Gabrielson DK, Scaffidi D, Leung E, et al. Use of an abridged scored Patient-Generated Subjective Global Assessment (abPG-SGA) as a nutritional screening tool for cancer patients in an outpatient setting. Nutr Cancer. 2013;65(2):234-239.

7. Xará S, Amaral TF, Parente B. [Undernutrition and quality of life in non small cell lung cancer patients]. Rev Port Pneumol. 2011;17(4):153-158.

8. Lis CG, Gupta D, Lammersfeld CA, Markman M, Vashi PG. Role of nutritional status in predicting quality of life outcomes in cancer-a systematic review of the epidemiological literature. Nutr J. 2012;11(1):27.

9. Kaikani W, Bachmann P. [Consequences of a comorbidity often neglected in oncology: malnutrition]. Bull Cancer. 2009;96(6):659-664.

10. Laky B, Janda M, Kondalsamy-Chennakesavan S, Cleghorn G, Obermair A. Pretreatment malnutrition and quality of life - association with prolonged length of hospital stay among patients with gynecological cancer: a cohort study. BMC Cancer. 2010;10(1):232.

11. Gupta D, Vashi PG, Lammersfeld CA, Braun DP. Role of nutritional status in predicting the length of stay in cancer: a systematic review of the epidemiological literature. Ann Nutr Metab. 2011;59(2-4):96-106.

12. Datema FR, Ferrier MB, Baatenburg de Jong RJ. Impact of severe malnutrition on short-term mortality and overall survival in head and neck cancer. Oral Oncol. 2011;47(9):910-914.

13. van Cutsem E, Arends J. The causes and consequences of cancerassociated malnutrition. Eur J Oncol Nurs. 2005;9(Suppl 2):S51-S63.

14. Detsky AS, McLaughlin JR, Baker JP, et al. What is Subjective Global Assessment of nutritional status? 1987. Classical article. Nutr Hosp. 2008;23(4):400-407.

15. Ottery FD. Definition of standardized nutritional assessment and interventional pathways in oncology. Nutrition. 1996;12(1 Suppl):S15-S19.

16. Jager-Wittenaar H, Ottery FD. Assessing nutritional status in cancer: role of the Patient-Generated Subjective Global Assessment. Curr Opin Clin Nutr Metab Care. 2017;20(5):322-329.

17. Barata AT, Santos C, Cravo M, et al. Handgrip dynamometry and PatientGenerated Subjective Global Assessment in patients with nonresectable lung cancer. Nutr Cancer. 2017;69(1):154-158.

18. Zhang L, Lu Y, Fang Y. Nutritional status and related factors of patients with advanced gastrointestinal cancer. BrJNutr. 2014;111(7):1239-1244.

19. Bauer J, Capra S, Ferguson M. Use of the scored Patient-Generated Subjective Global Assessment (PG-SGA) as a nutrition assessment tool in patients with cancer. Eur J Clin Nutr. 2002;56(8):779-785.

20. Ottery FD. Rethinking nutritional support of the cancer patient: the new field of nutritional oncology. Semin Oncol. 1994;21(6):770-778.
21. Ravasco P, Monteiro-Grillo I, Vidal PM, Camilo ME. Nutritional deterioration in cancer: the role of disease and diet. Clin Oncol ( $R$ Coll Radiol). 2003;15(8):443-450.

22. Leuenberger M, Kurmann S, Stanga Z. Nutritional screening tools in daily clinical practice: the focus on cancer. Support Care Cancer. 2010;18(Suppl 2): S17-S27.

23. van den Berg MG, Rasmussen-Conrad EL, van Nispen L, van Binsbergen JJ, Merkx MA. A prospective study on malnutrition and quality of life in patients with head and neck cancer. Oral Oncol. 2008;44(9):830-837.

24. Petruson KM, Silander EM, Hammerlid EB. Quality of life as predictor of weight loss in patients with head and neck cancer. Head Neck. 2005;27(4):302-310.

25. Capuano G, Gentile PC, Bianciardi F, Tosti M, Palladino A, Di Palma M. Prevalence and influence of malnutrition on quality of life and performance status in patients with locally advanced head and neck cancer before treatment. Support Care Cancer. 2010;18(4):433-437.

26. Mohan A, Singh P, Kumar S, et al. Effect of change in symptoms, respiratory status, nutritional profile and quality of life on response to treatment for advanced non-small cell lung cancer. Asian Pac J Cancer Prev. 2008;9(4):557-562.

27. Martin L, Birdsell L, Macdonald N, et al. Cancer cachexia in the age of obesity: skeletal muscle depletion is a powerful prognostic factor, independent of body mass index. J Clin Oncol. 2013;31(12): 1539-1547.

28. Kimura M, Naito T, Kenmotsu H, et al. Prognostic impact of cancer cachexia in patients with advanced non-small cell lung cancer. Support Care Cancer. 2015;23(6):1699-1708.

29. van Bokhorst-de van der Schueren MA, van Leeuwen PA, Sauerwein HP, Kuik DJ, Snow GB, Quak JJ. Assessment of malnutrition parameters in head and neck cancer and their relation to postoperative complications. Head Neck. 1997;19(5):419-425.

30. van Bokhorst-de van der Schuer MA, von Blomberg-van der Flier BM, Riezebos RK, et al. Differences in immune status between wellnourished and malnourished head and neck cancer patients. Clin Nutr. 1998;17(3):107-111.

31. Van Bokhorst-de Van der Schueren MA, Langendoen SI, Vondeling H, Kuik DJ, Quak JJ, Van Leeuwen PA. Perioperative enteral nutrition and quality of life of severely malnourished head and neck cancer patients: a randomized clinical trial. Clin Nutr. 2000;19(6):437-444.

32. Alifano M, Mansuet-Lupo A, Lococo F, et al. Systemic inflammation, nutritional status and tumor immune microenvironment determine outcome of resected non-small cell lung cancer. PLoS One. 2014;9(9):e106914.

33. Tan CS, Read JA, Phan VH, et al. The relationship between nutritional status, inflammatory markers and survival in patients with advanced cancer: a prospective cohort study. Support Care Cancer. $2015 ; 23(2): 385-391$.
Cancer Management and Research

\section{Publish your work in this journal}

Cancer Management and Research is an international, peer-reviewed open access journal focusing on cancer research and the optimal use of preventative and integrated treatment interventions to achieve improved outcomes, enhanced survival and quality of life for the cancer patient. The manuscript management system is completely online and includes

\section{Dovepress}

a very quick and fair peer-review system, which is all easy to use. Visit $\mathrm{http}: / / \mathrm{www}$.dovepress.com/testimonials.php to read real quotes from published authors. 